\title{
A CLASSE MÉdIA CHINESA E SEUS PADRÕES DE CONSUMO
}

Tradução de Markus Hediger

\section{INTRODUÇÃO}

A classe média na China como grupo com status social mais alto e melhores oportunidades de vida só veio a existir após as reformas de 1978. Na China antiga, os comerciantes foram excluídos da sociedade dominante durante muito tempo, como consequência da política social predominante de "fisiocracia e repressão ao comércio" (zhong nong yi shang). A "classe comercial e industrial" moderna foi moldada a partir do fim do século XIX até 1949, incluindo os comerciantes domésticos, os "mai ban" (pessoas empregadas por companhias estrangeiras), banqueiros e comerciantes dos ramos de manufatura e mineiração (Zhang, 2006). Após a revolução comunista de 1949, no entanto, a classe média foi destruída e reconstruída como classe operária socialista, que consistia de militantes do partido, intelectuais e funcionários de empresas estatais, estando incluída nesta categoria parte dos trabalhadores manuais (Li, 2001). Quando a China se voltou para a economia de mercado e a eficiência econômica se tornou a principal preocupação, a contribuição da classe média foi enfatizada em termos de sua inteligência produtiva e de sua dedicação ao consumo. A "classe média contemporânea" emergiu com as reformas, e a atividade profissional e o setor industrial tornaram-se as variáveis principais para distinguir a "classe média contemporânea" da "classe média" nos tempos de Mao, entre 1949 e 1977 (Li, 2001).

Em geral, o crescimento das economias privada e estrangeira, o desenvolvimento do setor terciário e o ressurgimento da educação superior são fatores importantes na expansão da população e na melhoria de suas oportunidades. Muitos acreditam que a classe média tem um impacto significativo sobre a emergência de uma cultura de consumo na China contemporânea (Wang, 2007: 8). Em primeiro lugar, é o grupo com maior poder econômico para impulsionar o consumo (Horizon, 2006: 462). Em segundo lugar, suas práticas de consumo incorporam novos gostos e novos desejos consumistas (Wang, 2007: 5-6). Por isto os padrões de consumo da classe média, tanto o consumo pessoal quanto 
familiar, têm atraído tanto interesse acadêmico. A literatura mostra que as cidades metropolitanas são importantes locais de criação de uma cultura consumista (Huang, Yang \& Lü, 2003; Liu, 2007). A percentagem de consumidores entre a classe média que possui um carro ou que vai adquirir carros no futuro próximo é muito mais alta do que a dos consumidores de classes mais baixas (Wang, 2007: 128). A classe média também participa com maior frequência de atividades de lazer, como ir à academia, do que a classe baixa (Wang, 2007: 148). Jovens (entre 18 e 28 anos de idade) são considerados os "consumidores mais ricos da China" pela posse de "bens de luxo"1 (Fan, 2000). Segundo Fan (2000: 90), isso se deve, por um lado, à ostentação do status familiar; por outro, ao fato de que alguns dos jovens que trabalham se encontram no topo da distribuição de renda como resultado da reforma econômica.

Devido a seu papel importante nessa sociedade em transição, este artigo voltará sua atenção às oportunidades de vida da classe média e aos seus padrões de consumo. A classe média é aqui definida com base principalmente nas profissões. Esse modelo de estratificação social será explicado mais adiante. Devido à expansão da cultura de consumo nas cidades metropolitanas, a classe média está preocupada. Após as reformas de 1978, as regiões do Leste (incluindo os três municípios de Pequim, Xangai, Tianjin e outras províncias costais), que possuem mais recursos naturais e são privilegiados pela política governamental, puderam se aproveitar melhor das oportunidades oferecidas pelo mercado e se transformaram nas regiões mais desenvolvidas. O PRB (Produto Regional Bruto) per capita na região Leste chegou a 3.514 dólares em 2006, enquanto o das regiões Central, Nordeste e Oeste chegou a 2.339, 1.573 e 1.403 dólares respectivamente (Wei, 2008). Por causa dessas diferenças econômicas regionais, o processo de acumulação de capital econômico, social e cultural, que em parte depende do meio familiar, pode ser diferente entre pessoas que nasceram em cidades metropolitanas e pessoas que imigraram de outras regiões. A literatura existente tende a focar nos "migrantes temporários" (Fan, 2001, 2002), nos migrantes sem formação profissional que executam trabalhos manuais, enquanto os "migrantes permanentes" têm recebido menos atenção (Fan, 2001, 2002, 2003; Fang et al., 2006). Estes são não nativos com boa formação e qualificação, que normalmente trabalham nos "setores formais", ou seja, para grandes e relativamente estáveis empregadores - organizações governamentais, empresas estatais, joint ventures, empresas cotadas na bolsa e empresas controladas por capital estrangeiro, de Hong Kong ou de Taiwan (Guo \& Iredale, 2004). Na China contemporânea, os "migrantes permanentes" nas cidades metropolitanas aumentaram muito em número, e suas oportunidades de vida, comparadas com as dos habitantes nativos numa posição social semelhante, precisam ser avaliadas.

Neste artigo empregarei a análise de correspondência múltipla (ACM) para examinar os padrões de consumo da classe média. Trata-se de um mé- 
todo de análise multivariada não linear, capaz de representar visualmente a correlação entre mais do que duas variáveis categóricas (Greenacre, 2006: 41-42). Não há nenhuma normalidade multivariada como suposição forçada em ACP (análise de componentes principais). Além disso, a ACM possui mais duas características que a destacam de outros métodos de escalonamento multidimensional. Em primeiro lugar, o impacto visual dos resultados pode ser interpretado facilmente. A distância entre duas categorias permite aos pesquisadores a inferência da proximidade de indivíduos de determinados tipos, por exemplo, as categorias "meia-idade" e "feminino" podem estar mais próximas uma da outra num gráfico. A contribuição de cada categoria para cada eixo permite aos pesquisadores a interpretação dos padrões revelados pelos dados. Em segundo lugar, após a elaboração dos mapas dos padrões de consumo, podem ser acrescentadas variáveis suplementares para associar os padrões a categorias demográficas sem mudar as coordenadas dos mapas originais. A ACM tem sido amplamente aplicada em pesquisas de mercado e estudos de capital cultural (veja Hoffman \& Leeuw, 1992; Gayo-Cal et al., 2006; Bennett et al., 2009), mas raramente tem sido usada para estudar a cultura de consumo na China. Neste artigo, empregarei essa técnica para mapear a participação da população urbana nas práticas de consumo.

Os dados foram retirados do China general social survey 2003 (CGSS, 2003). Este survey é representativo para as regiões, e suas unidades de amostragem primária são distritos urbanos e municípios da China continental, representando 22 províncias, quatro regiões autônomas e quatro municípios centrais ${ }^{2}$ (CGSS, 2003a: 1). A unidade da pesquisa é individual, a idade dos entrevistados está entre 18 e 69 anos (CGSS, 2003a). A amostragem válida totaliza 5.894 lares e apresenta um índice de resposta de $77 \%$. As informações dessa pesquisa incluem características demográficas dos entrevistados e seus lares, da rede social, nível de educação, histórico de carreira e do processo de busca do emprego atual, origens e destinos de cada migração, identidade, práticas de consumo e opiniões sobre desigualdade social e outros assuntos de interesse público (CGSS, 2003d; CGSS, 2003e). Em termos de método de seleção da amostragem, essa pesquisa combina a amostragem estratificada em cinco estágios com a amostragem de probabilidades proporcionais ao tamanho (PPT).

Como mencionado acima, os padrões de consumo são diferenciados principalmente por idade, renda, classe social e área de residência. Além disso, o crescimento da classe média na China contemporânea está intimamente ligado ao crescimento do setor terciário, especialmente ao novo setor terciário. Portanto, este artigo analisará as características da classe média e examinará seus padrões de consumo à luz da profissão, da área de residência, da idade, do sexo, da renda e da indústria.

Num primeiro passo, este artigo qualificará um conceito de "classe média" baseado em debates existentes e então procederá à definição das variáveis 
relevantes. Sua parte central é a ilustração das características da classe média e de seus padrões de consumo. Tomando a análise da pesquisa como base, as oportunidades de vida e a orientação do consumidor da classe média poderão ser inferidos.

\section{O CONCEITO DE "CLASSE MÉDIA"}

A qualificação do conceito de classe neste artigo diz respeito a como a análise de estratificação se desenvolveu e veio a ser aplicada nos estudos de estilo de vida e consumo. Os modelos de classe desenvolvidos por Marx e Weber são duas das teorias com maior influência. Marx define classe em termos de relações de trabalho, ou seja, a propriedade dos meios de produção estabelece uma relação de exploração. O modelo de classe de Marx, portanto, pode ser visto como modelo produtivista, em que outras áreas da vida, incluindo o consumo, são determinadas pela propriedade dos meios de produção. Baseado nesse mecanismo, a sociedade capitalista como um todo se divide cada vez mais em duas grandes classes hostis: a burguesia e o proletariado (Marx, 1848). Assim, Marx não identifica uma "classe média" ou "classes intermediárias" dentro da sociedade, que exercem algum controle sobre os meios de produção, mas são excluídas do controle sobre o capital monetário. Diferentemente de Marx, Weber argumenta que os mecanismos do mercado são responsáveis pela estratificação social e classifica as pessoas de acordo com seus recursos e seu acesso aos recursos para a obtenção de bem-estar no mercado (Sorensen, 1994). Weber não acredita que classe ou riqueza econômica seja o fator principal da estratificação social. Antes, sugere um modelo de estratificação que combina classe com status (reputação e estima) e poder (poder político). Essa abordagem multidimensional é mais eficiente como definição da classe média. A classe média consiste de pessoas que têm alguma propriedade, mas pouca formação (o "pequeno-burguês", como donos de pequenas lojas e pequenos empreendedores) e de pessoas que possuem pouco, mas que podem exigir altos salários em virtude de sua formação e qualificação (os "intelectuais e especialistas") (Saunders, 1990: 22). Weber, portanto, sugere uma noção importante, segundo a qual a estratificação social não depende unicamente do capital econômico, mas também do capital cultural e do estilo de vida. A relação entre posição social e educação é assim constituída.

Se adotarmos o conceito de Bourdieu, o capital cultural age como relação social dentro de um sistema de troca que inclui o conhecimento cultural acumulado, que confere poder e status (Bourdieu, 1986). Com relação ao importante papel do capital cultural para a estratificação social, Weber exerce uma grande influência sobre a visão que Bourdieu tem da classe social. Segundo Bourdieu (1984: 373), "a classe social não é definida unicamente pela posição dentro das 
relações de produção, mas pelo habitus da classe que 'normalmente' (ou seja, com grande probabilidade estatística) é associado a essa posição". Bourdieu (1990: 53) explica habitus como "sistema de disposições duráveis e transponíveis, como estruturas estruturadas predispostas a funcionarem como estruturas estruturantes". Como "estruturas estruturadas", o habitus é definido por duas formas de capital principais: o capital econômico e o capital cultural, e ajuda a reproduzir essas formas de capital. O capital econômico pode "imediata e diretamente ser convertido em dinheiro e pode ser institucionalizado em formas de direito de propriedade" (Bourdieu, 1986: 3). Como Marx, Bourdieu também reconhece o capital econômico como fator fundamental, que se encontra "na raiz de todos os outros tipos de capital", e que "os diferentes tipos de capital podem ser derivados do capital econômico" (Bourdieu, 1986: 12-13). O capital cultural "pode ser convertido, sob certas condições, em capital econômico e pode ser institucionalizado em formas de qualificações educacionais" (Bourdieu, 1986: 3). Como "estruturas estruturantes", o habitus organiza o consumo e os estilos de vida, e os gostos são as realizações subjetivas do mecanismo do habitus (Sassatelli, 2007: 92). Gostos funcionam como "poder simbólico" por meio do qual "classificações objetivas" vêm a coincidir com "classificações subjetivas", permitindo assim a "naturalização" de ordem social e cultural (Sassatelli, 2007: 94).

Mais recentemente, os trabalhos de Chan \& Goldthorpe (2007a, 2007b) têm chamado a atenção para os efeitos do status na estratificação social. Apesar de rejeitarem o argumento de Bourdieu sobre a dominação cultural, sua análise compartilha com Bourdieu a ênfase do capital cultural e até do capital social, além do capital econômico, na estratificação do consumo cultural. As posições de status são vistas como "resultantes das relações entre igualdade e desigualdade social, expressas em formas mais íntimas de associação e, particularmente, em 'comensalidade' e 'conúbio' - em quem come com quem e quem dorme com quem" (Chan \& Goldthorpe, 2007a: 377). A estrutura de classe, resultante das relações sociais na vida econômica, e a ordem de status são entendidas como formas de estratificação social qualitativamente diferentes (Chan \& Goldthorpe, 2007a: 377). Suas pesquisas favorecem o argumento "onívoro-unívoro", segundo o qual as pessoas de camadas sociais mais altas apresentam uma probabilidade maior de participação numa ampla gama de práticas culturais (Chan \& Goldthorpe, 2007a, 2007b). Quanto à estratificação do consumo musical, tornou-se claro que o status é mais importante do que a classe (Chan \& Goldthorpe, 2007b: 10). Além disso, sugere-se que o status opera de forma independente na estratificação do consumo cultural (1) no teatro, dança e cinema, (2) na música e (3) nas artes visuais, pois o status ainda exerce frequentemente um efeito maior sobre o nível e a forma do consumo cultural do que os efeitos de educação e renda (Chan \& Goldthorpe, 2007a: 382).

Tendo examinado os debates sobre estratificação social, este artigo ainda considera ser a classe, baseada em relações econômicas, uma estrutura impor- 
tante na diferenciação de práticas de consumo, especialmente no contexto de países em desenvolvimento. Argumenta-se que as escalas de "status ocupacional" possam medir semelhanças básicas de estilo de vida, porque as circunstâncias sociais e materiais estão intimamente associadas à experiência ocupacional, portanto as escalas podem também medir os resultados do mercado de trabalho associados ao sistema de produção (Stewart et al., 1980). Os resultados do mercado de trabalho são particularmente evidentes em países em desenvolvimento, fato que pode ser encontrado em grande número de estudos de pesquisas de mercado, sociologia e antropologia sobre a cultura e os padrões de consumo da classe média. A classe média chinesa com seu status social especial na sociedade contemporânea também ocupa um papel importante na emergência da cultura de consumo. Por isso, baseado na literatura mencionada acima, este artigo se propõe a estudar a estratificação das práticas de consumo, com base na classe e com o foco voltado para a classe média na China.

\section{MEDIÇÕES DE VARIÁVEIS-CHAVE}

A classe social é operacionalizada como classe ocupacional. Mesmo que a classe social também possa ser associada à posição ou ao tamanho do empregador, a ocupação contém a informação mais útil para a distinção social. Além disso, algumas das categorias de ocupação da pesquisa indicam também posições dentro da hierarquia de trabalho. As variáveis ocupacionais da pesquisa provêm de variáveis de séries temporais que reúnem informações sobre empregos em sequência histórica desde o primeiro emprego até o emprego atual, com um máximo de doze empregos (CGSS, 2003d: 16). Os códigos para as ocupações seguem o padrão estabelecido pelo Occupation classification and codes 2000 (CGSS, 2003d), que explicitamente enumera até 999 ocupações, inclusive emprego, autoemprego e desemprego. Para maior conveniência, as 999 ocupações são divididas em sete categorias, empregando-se simplesmente os sete títulos do esquema de classificação (CGSS, 2003f), descritos na Tabela 1.

A categoria "Dirigentes do partido, organizações e instituições governamentais" inclui proprietários de empresas e executivos, e a categoria "Profissionais e técnicos, funcionários comuns e em posição intermediária do governo" inclui ocupações profissionais e funcionários públicos. Portanto, neste artigo as primeiras duas categorias são definidas como "classe média"; e as outras cinco, como "classe baixa". Como mostra a Tabela 2, a percentagem da classe média na China urbana em 2003 é de 16,4\%. Essa estimativa, que não inclui a população rural, é ligeiramente mais alta do que os $15,9 \%^{5}$ calculados por Li (2003).

A população metropolitana, com a divisão entre migrantes e nativos, é definida como o conjunto de pessoas que vivem permantentemente ${ }^{6}$ nos distritos urbanos dos três municípios centrais, Pequim, Xangai e Tianjin. ${ }^{7}$ Ao combinar 


\section{Categorias de ocupação}

\begin{tabular}{l|r}
\hline Dirigentes do partido, organizações e instituições governamentais & 2,9 \\
\hline $\begin{array}{l}\text { Profissionais e técnicos, funcionários comuns e } \\
\text { em posição intermediária do governo }\end{array}$ & 13,5 \\
\hline Pequenos empregadores e operários autoempregados $^{4}$ & 9,9 \\
\hline Empregados de escritório e semelhantes & 7,6 \\
\hline Empregados de comércio e serviço & 10,7 \\
\hline Empregados florestais, de fazenda, criação, pesca e recursos aquáticos & 1,5 \\
\hline Operadores de equipamentos de produção e transporte e semelhantes & 17,8 \\
\hline Desempregados e que nunca trabalharam & 36,1 \\
\hline Total & $\mathbf{1 0 0 , 0}$
\end{tabular}

Tabela 1: Percentagem da população por ocupação na China urbana, 2003

Fonte: China general social survey 2003.

População: Todos os homens e mulheres entre 15 e 77 anos, que de fato residem na China urbana em 2003.

Base: 5.894 .

Taxa de resposta: $77 \%$.

Peso: O peso combinado, usando-se sexo e idade baseados em estatísticas do quinto censo de 2000.

Válidos: 5.339.

Categorias de ocupação

\begin{tabular}{l|r}
\hline Classe média & 16,4 \\
\hline Classe baixa & 83,6 \\
\hline Total & $\mathbf{1 0 0 , 0}$
\end{tabular}

Tabela 2: Percentagem da população por classe ocupacional, China urbana, 2003

Fonte: China general social survey 2003.

População: Todos os homens e mulheres entre 15 e 77 anos, que de fato residem na China urbana em 2003

Base: 5.894 .

Taxa de resposta: $77 \%$.

Peso: o peso combinado, usando-se sexo e idade baseados em estatísticas do quinto censo de 2000.

Válidos: 5.339. 
informações das variáveis sobre migração, estratos de amostragem, local de registro da residência e registro da localização da residência permanente, este artigo divide os entrevistados desta pesquisa sobre residentes de áreas urbanas em três categorias: (1) "migrantes metropolitanos", pessoas que migraram para cidades metropolitanas por ocasião de sua migração mais recente, sendo que sua primeira migração partiu de cidades não metropolitanas; (2) "nativos metropolitanos", com duas subcategorias: (a) pessoas que não apresentam nenhuma experiência de migração, selecionadas de cidades metropolitanas e entrevistadas naquele endereço, naquela cidade ou distrito, ou cidade com nível de distrito ou naquele município, e que tenham registro de residência urbano, e (b) pessoas que migraram para uma das cidades metropolitanas por ocasião de sua mais recente migração, sendo que a primeira migração partiu desta ou de alguma outra cidade metropolitana; e (3) "outros residentes urbanos", pessoas que não se encaixam em uma das duas primeiras categorias. ${ }^{8}$ De acordo com esse esquema, a população nacional se apresenta de acordo com a Tabela 3.

Na Tabela 4, vemos que $14,8 \%$ da população nas cidades metropolitanas pertencem à classe média. Esta percentagem é um pouco menor do que a percentagem da classe média em regiões urbanas (16,4\%), fato que "contradiz" o "senso comum", já que se pensa que as cidades metropolitanas acomodam mais (ou pelo menos o mesmo tanto de) classe média e, portanto, a percentagem da classe média das cidades metropolitanas deveria ser mais alta (ou pelo menos semelhante) à percentagem da classe média no total das regiões urbanas. Talvez um dos motivos possa ser encontrado na pequena amostragem da população metropolitana, que leva a uma estimativa enviesada. Outro motivo possível talvez possa ser encontrado na classificação das categorias ocupacionais, que espalhou um grande número de ocupações da classe média nas outras regiões urbanas. No entanto, a diferença na percentagem da classe média das duas populações é insignificante, como mostram as Estatísticas F. 


\begin{tabular}{l|r} 
Categorias da população & Percentagem \\
\hline Migrantes metropolitanos & 0,8 \\
\hline Nativos metropolitanos & 6,4 \\
\hline Outros residentes urbanos & 92,8 \\
\hline Total & $\mathbf{1 0 0 , 0}$
\end{tabular}

Tabela 3: Percentagem da população por área de residência, China urbana, 2003

Fonte: China general social survey 2003.

População: Todos os homens e mulheres entre 15 e 77 anos, que de fato residem na China urbana em 2003

Base: 5.894 .

Taxa de resposta: $77 \%$.

Peso: o peso combinado, usando-se sexo e idade baseados em estatísticas do quinto censo de 2000.

\begin{tabular}{l|r|r} 
Categorias de classe social & População metropolitana & $\begin{array}{l}\text { População } \\
\text { não metropolitana }\end{array}$ \\
\hline Classe média & 14,8 & 16,6 \\
\hline Classe baixa & 85,2 & 83,4 \\
\hline Total & $\mathbf{1 0 0 , 0}$ & $\mathbf{1 0 0 , 0}$
\end{tabular}

Tabela 4: Percentagem da população por classe social e área de residência, China urbana, 2003

Fonte: China General Social Survey 2003.

População: Todos os homens e mulheres entre 15 e 77 anos, que de fato residem na China urbana em 2003.

Base: 5.894 .

Taxa de resposta: $77 \%$.

Peso: o peso combinado, usando-se sexo e idade baseados em estatísticas do quinto censo de 2000 .

Válidos: 5.339

chi2(1) não corrigido $=0,8094$.

${ }^{*}$ Design-based $\mathrm{F}(1,98)=0,4275 \mathrm{P}=0,5148$. 


\section{CARACTERÍSTICAS DA CLASSE MÉDIA EM CIDADES METROPOLITANAS}

Nesta seção, ilustrarei as características demográficas da classe média nas cidades metropolitanas, considerando ocupação, idade, sexo, renda e indústria. A distinção entre migrantes e nativos é uma preocupação essencial, já que demonstrará se a origem de residência acarretaria qualquer diferença ou obstáculo na conquista de status social.

Como descrito na Tabela 5, a percentagem da classe média entre migrantes metropolitanos (22,9\%) é mais alta do que entre nativos metropolitanos $(13,7 \%)$. A diferença se deve principalmente à percentagem mais alta de "ocupações profissionais e técnicas" entre os migrantes do que entre os nativos. Essa constatação reflete o fato de que as pessoas que se mudam para a metrópole tendem a apresentar mais motivação para alcançar um status social mais alto, comparado àqueles que nasceram na metrópole. Nota-se também que nenhum migrante metropolitano tinha uma ocupação da elite social, como dirigente do partido ou governo, de empresas, organizações e instituições. Uma possível razão para isso pode ser a pequena amostragem de migrantes metropolitanos que leva a um viés na estimativa. Mesmo assim, podemos resumir que a maioria da classe média nas cidades metropolitanas se encontra em ocupações profissionais e técnicas ou é funcionário público, com uma percentagem maior de classe média entre os migrantes do que entre os nativos.

A Tabela 6 revela que migrantes metropolitanos com ocupações como "Profissionais e técnicos, funcionários comuns e em posição intermediária do governo" são normalmente mais jovens do que os nativos metropolitanos com as mesmas ocupações, em média, 32 versus 41 anos de idade. Uma das razões para isso é que, no grupo de migrantes metropolitanos, não se observa elites sociais, que tendem a ser mais velhas; por exemplo, a idade média para os nativos serem "dirigentes do partido, organizações e instituições governamentais" é de aproximadamente 46 anos. Mesmo assim, grupos de idade podem revelar diferenças mais sutis entre migrantes e nativos. 


\begin{tabular}{|c|c|c|}
\hline Categorias ocupacionais & $\begin{array}{l}\text { Migrantes } \\
\text { metropolitanos (\%) }\end{array}$ & $\begin{array}{l}\text { Nativos } \\
\text { metropolitanos (\%) }\end{array}$ \\
\hline $\begin{array}{l}\text { Dirigentes do partido, organizações e } \\
\text { instituições governamentais }\end{array}$ & 0 & 1,2 \\
\hline $\begin{array}{l}\text { Profissionais e técnicos, funcionários comuns e } \\
\text { em posição intermediária do governo }\end{array}$ & 22,9 & 12,5 \\
\hline Classe média & 22,9 & 13,7 \\
\hline $\begin{array}{l}\text { Pequenos empregadores e operários } \\
\text { autoempregados }\end{array}$ & 1,3 & 2,0 \\
\hline Empregados de escritório e semelhantes & 11,6 & 9,9 \\
\hline Empregados de comércio e serviço & 6,6 & 13,0 \\
\hline $\begin{array}{l}\text { Empregados florestais, de fazenda, criação, pesca } \\
\text { e recursos aquáticos }\end{array}$ & 0 & 0,8 \\
\hline $\begin{array}{l}\text { Operadores de equipamentos de produção e } \\
\text { transporte e semelhantes }\end{array}$ & 10,7 & 19,2 \\
\hline Desempregados e que nunca trabalharam & 47,0 & 41,42 \\
\hline Classe baixa & 77,1 & 86,3 \\
\hline Total & 100,0 & 100,0 \\
\hline
\end{tabular}

Tabela 5: Percentagem da população por ocupação nas cidades metropolitanas, China, 2003

Fonte: China general social survey 2003.

População: Todos os homens e mulheres entre

15 e 77 anos, que de fato residem na China urbana em 2003.

Base: 5.894. Taxa de resposta: $77 \%$.

Peso: o peso combinado, usando-se sexo e idade baseados em estatísticas do quinto censo de 2000.

Válidos: 116 para migrantes metropolitanos e 779 para nativos metropolitanos.

\begin{tabular}{l|l|l} 
Categorias ocupacionais & $\begin{array}{l}\text { Migrantes } \\
\text { metropolitanos }\end{array}$ & $\begin{array}{l}\text { Nativos } \\
\text { metropolitanos }\end{array}$ \\
\hline $\begin{array}{l}\text { Dirigentes do partido, organizações e instituições } \\
\text { governamentais }\end{array}$ & $\cdot$ & 46 \\
\hline $\begin{array}{l}\text { Profissionais e técnicos, funcionários comuns e } \\
\text { em posição intermediária do governo }\end{array}$ & 32 & 40 \\
\hline Classe média & $\mathbf{3 2}$ & $\mathbf{4 1}$
\end{tabular}

Tabela 6: Idade média da população da classe média em cidades metropolitanas, China, 2003

Fonte: China general social survey 2003.

População: Todos os homens e mulheres entre 15 e 77 anos, que de fato residem na China urbana em 2003.

Base: 5.894.Taxa de resposta: 77\%.

Peso: o peso combinado, usando-se sexo e idade baseados

em estatísticas do quinto censo de 2000.

Válidos: 27 para migrantes metropolitanos e 107 para nativos metropolitanos. 
A Tabela 7 mostra que a maioria (39,8\% e 44,0\%) dos migrantes metropolitanos estão na faixa de idade entre 18 e 35 anos, com ocupações como "Profissionais e técnicos, funcionários comuns e em posição intermediária do governo". Em contraste, os nativos metropolitanos com ocupações semelhantes se dividem de forma mais equilibrada entre os grupos de idade, e os grupos de idade de 18-25 e de 46-55 anos são ligeiramente predominantes, representando $24,65 \%$ e $21,64 \%$ respectivamente. Os nativos metropolitanos "dirigentes", como mostra a Tabela 7, são um pouco mais velhos do que os outros nativos da classe média, sendo que 61,4\% têm entre 46 e 55 anos de idade. Está implícito no fato de os migrantes da classe média serem mais jovens do que os nativos da classe média que ser mais jovem representa uma vantagem para a população migrante das cidades metropolitanas em termos de mobilidade social. O motivo para isso é, possivelmente, que o jovem está normalmente associado a uma educação e um trabalho superior na nova indústria, cujas condições possibilitam um acesso mais fácil a um status social mais alto. A idade, porém, é menos importante para a população nativa para sua mobilidade social, pois podem recorrer a outros recursos como, por exemplo, a rede social familiar.

No que diz respeito às ocupações "profissionais", há mais homens do que mulheres em ambas as populações metropolitanas, apesar de a diferença entre os sexos ser um pouco mais aparente entre os migrantes metropolitanos, como se vê na Tabela 8. Por outro lado, há muito mais homens do que mulheres ocupando cargos de "dirigentes" entre os nativos metropolitanos $(76,1 \%$ versus $23,9 \%$ ). De acordo com o Teste $F$, as diferenças entre os sexos em relação às duas ocupações de classe média entre a população nativa são estatisticamente insignificantes. ${ }^{9}$ Assim fica evidente que, em geral, existe uma igualdade entre homens e mulheres em termos de acesso a empregos profissionais e executivos, enquanto as ocupações de elite permanecem dominadas por homens.

De acordo com a Tabela 9, a renda anual da classe média em cidades metropolitanas se concentra entre 10 mil e 60 mil yuan em 2002. ${ }^{10}$ Apresentam uma renda anual dentro dessa faixa aproximadamente $95 \%(55,1 \%+39,6 \%)$ de "dirigentes" e $89 \%(27,7 \%+61,6 \%)$ de "profissionais" dentre os nativos, e $80 \%$ $(36,8 \%+42,5 \%)$ de "profissionais" dentre os migrantes. Apesar de mais nativos do que migrantes terem aquela renda anual, encontramos mais migrantes $(13,8 \%)$ do que nativos $(4,1 \%)$ no grupo de renda alta de 60 mil yuan ou mais. Quanto ao grupo de renda baixa "abaixo de 5 mil yuan", nenhuma observação foi feita entre "dirigentes" de ambas as populações, enquanto há mais migrantes "profissionais" (5\%) do que nativos "profissionais" (0,4\%) que se enquadrem aqui. É preciso enfatizar que as estatísticas de renda estão sujeitas ao risco de subestimação, já que a experiência mostra que o povo chinês tende a ser cuidadoso ou conservador ao relatar sua renda a pessoas estranhas. 


\begin{tabular}{l|l|l|l|l|l|l} 
Migrantes metropolitanos & \multicolumn{3}{l}{ Grupos de idade (\%) } \\
\hline Nativos metropolitanos & $\mathbf{1 5 - 2 5}$ & $\mathbf{2 6 - 3 5}$ & $\mathbf{3 6 - 4 5}$ & $\mathbf{4 6 - 5 5}$ & $\mathbf{5 6 - 7 7}$ & Total \\
\hline $\begin{array}{l}\text { Dirigentes do partido, organizações e } \\
\text { instituições governamentais }\end{array}$ & 0 & 0 & 0 & 0 & 0 & 0 \\
\cline { 2 - 8 } & 0 & 10,5 & 25,5 & 64,1 & 0 & 100 \\
\hline $\begin{array}{l}\text { Profissionais e técnicos, funcionários } \\
\text { comuns e em posição intermediária do } \\
\text { governo }\end{array}$ & 39,8 & 44,0 & 3,3 & 3,9 & 9,0 & 100 \\
\hline & 24,7 & 18,3 & 19,0 & 21,6 & 16,5 & 100 \\
\hline Classe média & 39,8 & 44,0 & 3,3 & 3,9 & 9,0 & 100 \\
\cline { 2 - 8 } & 22,5 & 17,6 & 19,6 & 25,3 & 15,0 & 100
\end{tabular}

Tabela 7: Percentagem da população da classe média por grupos de idade em cidades metropolitanas, China, 2003

Fonte: China general social survey 2003.

População: Todos os homens e mulheres entre 15 e 77 anos, que de fato residem na China urbana em 2003.

Base: 5.894 . Taxa de resposta: $77 \%$.

Peso: o peso combinado, usando-se sexo e idade baseados em estatísticas do quinto censo de 2000.

Válidos: 27 para migrantes metropolitanos e 107 para nativos metropolitanos.

\begin{tabular}{|c|c|c|c|}
\hline Migrantes metropolitanos & \multirow[t]{2}{*}{ Homens (\%) } & \multirow[t]{2}{*}{ Mulheres (\%) } & \multirow[t]{2}{*}{ Total } \\
\hline Nativos metropolitanos & & & \\
\hline \multirow{2}{*}{$\begin{array}{l}\text { Dirigentes do partido, organizações e instituições } \\
\text { governamentais }\end{array}$} & 0 & 0 & 0 \\
\hline & 76,1 & 23,9 & 100 \\
\hline \multirow{2}{*}{$\begin{array}{l}\text { Profissionais e técnicos, funcionários comuns e em } \\
\text { posição intermediária do governo }\end{array}$} & 68,5 & 31,5 & 100 \\
\hline & 54,2 & 43,8 & 100 \\
\hline \multirow[t]{2}{*}{ Classe média } & 68,5 & 31,5 . & 100 \\
\hline & $56,2^{*}$ & $43,8^{*}$ & 100 \\
\hline
\end{tabular}

Tabela 8: Percentagem da população de classe média em cidades metropolitanas por sexo, China, 2003

Fonte: China general social survey 2003.

População: Todos os homens e mulheres entre 15 e 77 anos, que de fato residem na China urbana em 2003.

Base: 5.894. Taxa de resposta: 77\%.

Peso: o peso combinado, usando-se sexo e idade baseados em estatísticas do quinto censo de 2000.

Válidos: 26 para migrantes metropolitanos e 125 para nativos metropolitanos.

${ }^{*}$ Design-based $\mathrm{F}(1,12)=2.2351 \mathrm{P}=0.1607$, baseado em 125 observações. 
Aplica-se o Teste F com o "peso combinado" a fim de comparar as diferenças de renda entre os migrantes de classe média e os nativos de classe média. Como ilustrado pela Tabela 10, poder-se-ia inferir do valor $\mathrm{P}$ de 0,3834 que não existe diferença significativa entre os dois grupos. Daí se deduz que a origem de residência não representa uma barreira para a conquista de uma renda alta em cidades metropolitanas. As diferenças causadas pela origem de residência podem ser encontradas no acesso a empregos de elite ou na indústria, como demonstraremos mais adiante. Uma vez que uma pessoa é recrutada, seu status de migrante ou nativo não mais representaria um fator decisivo para explicar a diferença em termos de renda.

Já que não foi observado nenhum caso de ocupação de elite entre os migrantes e existem 14 categorias de indústria, as subcategorias de ocupações da classe média foram integradas de modo a representarem uma tabulação cruzada mais condensada. De acordo com a Tabela 11, a distribuição industrial da classe média entre migrantes e nativos metropolitanos é bastante análoga. As três maiores categorias para ambas as populações são "manufatura e distribuição de energia", "educação, comunicação e pesquisa científica" e "órgãos do Estado, do partido e do partido democrático". Portanto, pode-se ver que a indústria tradicional ainda domina as ocupações da classe média na China metropolitana. Indústrias tradicionais em particular, como "manufatura e distribuição de energia", "varejo e atacado" e "transporte, armazenagem, correios e telecomunicação" reúnem mais nativos do que migrantes nas cidades metropolitanas. Isso faz sentido, porque os nativos têm um acesso mais fácil a esses setores por herdá-los de seus pais ${ }^{11}$ ou serem levados a eles por familiares. 0 novo setor terciário, porém, que veio a existir após as reformas econômicas, também está florescendo, como pode ser visto na Tabela 11. A indústria de "consultoria e de serviços TI" atrai 13\% dos migrantes da classe média e 8,9\% dos nativos da classe média. Além disso, "serviços imobiliários e residenciais" e "finanças e seguros" acomodam $7 \%$ dos migrantes da classe média e $8 \%$ dos nativos da classe média. Não existe diferença significativa na alocação das duas populações no novo setor terciário. Portanto, a CGSS 2003 confirmou ser o novo setor terciário um espaço para cultivar um número considerável de membros da classe média contemporânea, como já fora sugerido pela literatura existente. 


\begin{tabular}{|c|c|c|c|c|c|c|}
\hline \multirow{2}{*}{$\begin{array}{l}\text { Migrantes metropolitanos } \\
\text { Nativos metropolitanos }\end{array}$} & \multicolumn{6}{|c|}{ Grupo de renda (\%) } \\
\hline & $\begin{array}{l}60 \mathrm{mil} \mathrm{e} \\
\text { acima }\end{array}$ & $\begin{array}{l}\text { Entre } 30 \\
\text { e } 60 \mathrm{mil}\end{array}$ & $\begin{array}{l}\text { Entre } 10 \\
\text { e } 30 \mathrm{mil}\end{array}$ & $\begin{array}{l}\text { Entre } 5 \\
\text { e } 10 \mathrm{mil}\end{array}$ & $\begin{array}{l}\text { Abaixo } \\
\text { de } 5 \text { mil }\end{array}$ & Total \\
\hline \multirow{2}{*}{$\begin{array}{l}\text { Dirigentes do partido, } \\
\text { organizações e instituições } \\
\text { governamentais }\end{array}$} & 0 & 0 & 0 & 0 & 0 & 100 \\
\hline & 5,4 & 55,1 & 39,6 & 0 & 0 & 100 \\
\hline \multirow{2}{*}{$\begin{array}{l}\text { Profissionais e técnicos, } \\
\text { funcionários comuns e em } \\
\text { posição intermediária do } \\
\text { governo }\end{array}$} & 13,8 & 36,8 & 42,5 & 1,9 & 5,0 & 100 \\
\hline & 4,1 & 27,7 & 61,6 & 6,1 & 0,4 & 100 \\
\hline \multirow[t]{2}{*}{ Classe média } & 13,8 & 36,8 & 42,5 & 1,9 & 5,0 & 100 \\
\hline & 4,2 & 30,0 & 59,7 & 5,6 & 0,4 & 100 \\
\hline
\end{tabular}

Tabela 9: Percentagem da população da classe média em cidades metropolitanas por ocupação e grupos de renda, China, 2003 Fonte: China general social survey 2003.

População: Todos os homens e mulheres entre 15 e 77 anos, que de fato residem na China urbana em 2003.

Base: 5.894 . Taxa de resposta: $77 \%$.

Peso: o peso combinado, usando-se sexo e idade baseados em estatísticas do quinto censo de 2000.

Válidos: 21 para migrantes metropolitanos e 90 para nativos metropolitanos.

\begin{tabular}{l|r|r} 
Grupo de renda & \multicolumn{1}{|l}{$\begin{array}{l}\text { Migrantes } \\
\text { metropolitanos (\%) }\end{array}$} & $\begin{array}{l}\text { Nativos } \\
\text { metropolitanos (\%) }\end{array}$ \\
\hline 60 mil e acima & 12,9 & 4,3 \\
\hline Entre 30 mil e 60 mil & 34,4 & 27,6 \\
\hline Entre 10 mil e 30 mil & 39,7 & 58,8 \\
\hline Entre 5 mil e 10 mil & 8,4 & 6,4 \\
\hline Abaixo de 5 mil & 4,7 & 2,9 \\
\hline Total & $\mathbf{1 0 0}$ & $\mathbf{1 0 0}$
\end{tabular}

Tabela 10: Percentagem da população de classe média nas cidades metropolitanas por grupos de renda, China, 2003

Fonte: China general social survey 2003.

População: Todos os homens e mulheres entre 15 e 77 anos, que de fato residem na China urbana em 2003.

Base: 5.894. Taxa de resposta: $77 \%$.

Peso: o peso combinado, usando-se sexo e idade baseados

em estatísticas do quinto censo de 2000.

Válidos: 140 migrantes e nativos.

Design-based $F(3.06,36.72)=1.0491 \mathrm{P}=0.3834$. 
Até agora, obtivemos uma imagem da classe média na China metropolitana do início dos anos 2000. A maioria da população tem empregos profissionais ou técnicos ou pertence ao quadro governamental, pode ser tanto masculina quanto feminina e apresenta uma renda anual entre $10 \mathrm{mil}$ e $60 \mathrm{mil}$ yuan. As diferenças entre migrantes e nativos da classe média são encontradas principalmente em suas ocupações, na idade e nas indústrias em que trabalham, mas não em sua renda. Entende-se dos dados quantitativos que a população nativa tem um acesso melhor às ocupações da classe média (por exemplo, a percentagem maior de ocupações de elite e de pessoas que trabalham em indústrias tradicionais), mas que não é privilegiada na conquista de status social. Além disso, a população migrante apresenta mais motivação para conquistar uma mobilidade social ascendente, refletida na percentagem maior de migrantes mais jovens encontrados na classe média. As diferenças insignificantes em termos de mobilidade social entre migrantes e nativos têm consequências importantes para seus padrões de consumo menos divergentes, como será mostrado em seguida.

\section{PADRÕES DE CONSUMO DA CLASSE MÉDIA}

Esta seção analisará a proximidade e distância da participação em práticas de consumo entre a população urbana, possibilitada pela análise de correspondência múltipla. Pode-se entender a orientação do consumidor da população urbana e como esta é diferenciada por indicadores socioeconômicos.

\section{O levantamento da participação em práticas de consumo}

Nos dados da pesquisa há um conjunto de variáveis sobre a participação em atividades pessoais e sociais. Selecionei seis variáveis sobre a aquisição e o uso de bens e serviços materiais para criar a possibilidade de medir a participação de cada entrevistado em alguma aquisição comum de bens "desnecessários", como comer em um restaurante, o uso de produtos de marca, compras em lojas de departamentos, o uso de bens culturais em casa e a frequência a academias. Pode-se ver que essa pesquisa tenta medir a orientação do consumidor entre a população urbana, que é também o foco deste artigo. Os rótulos de valores originais dos dados são escalas de concordância. As opções de resposta são: "altamente apropriado", "relativamente apropriado", "relativamente inapropriado" e "altamente inapropriado" para cada tipo de consumo mencionado acima. ${ }^{12}$ As escalas de concordância foram recodificadas como escalas de frequência, sendo que os rótulos das variáveis também foram adaptados. Quanto às escalas departicipação em práticas de consumo, 1 significa frequentemente; 2 , às vezes; 3, ocasionalmente; e 4, nunca. Assim, este artigo usa seis variáveis com quatro categorias ordinais para cada variável, que gera 24 modalidades na análise de correspondência múltipla. 


\begin{tabular}{|c|c|c|}
\hline \multirow[t]{2}{*}{ Categorias de indústrias } & \multicolumn{2}{|l|}{ Classe média } \\
\hline & $\begin{array}{l}\text { Migrantes } \\
\text { metropolitanos (\%) }\end{array}$ & $\begin{array}{l}\text { Nativos } \\
\text { metropolitanos (\%) }\end{array}$ \\
\hline Agricultura e mineiração & 0 & 0,8 \\
\hline Manufatura e distribuição de energia & 10,1 & 15,2 \\
\hline Construção e engenharia civil & 8,3 & 5,4 \\
\hline $\begin{array}{l}\text { Transporte, armazenagem, correios e } \\
\text { telecomunicação }\end{array}$ & 0 & 8,0 \\
\hline Varejo e atacado & 3,8 & 6,9 \\
\hline Finanças e seguros & 5,3 & 2,5 \\
\hline Serviços imobiliários e residenciais & 1,9 & 5,7 \\
\hline Turismo e entretenimento & 0 & 0 \\
\hline Consultoria e serviços TI & 12,9 & 8,8 \\
\hline Serviços sociais & 0 & 5.2 \\
\hline $\begin{array}{l}\text { Educação, cultura, comunicação e } \\
\text { pesquisa científica }\end{array}$ & 37,0 & 26,8 \\
\hline $\begin{array}{l}\text { Órgãos do Estado, do partido e do partido } \\
\text { democrático }\end{array}$ & 20,7 & 12,0 \\
\hline Organizações sociais & 0 & 1,9 \\
\hline Outras & 0 & 0,9 \\
\hline Total & 100 & 100 \\
\hline
\end{tabular}

Tabela 11: Percentagem da população da classe média nas cidades metropolitanas por indústria, China, 2003

Fonte: China general social survey 2003.

População: Todos os homens e mulheres entre 15 e 77 anos, que de fato residem na China urbana em 2003.

Base: 5.894 .

Taxa de resposta: $77 \%$.

Peso: o peso combinado, usando-se sexo e idade baseados em estatísticas do quinto censo de 2000.

Válidos: 26 para migrantes metropolitanos e 120 para nativos metropolitanos. 


\section{O uso da Análise de Correspondência Múltipla - ACM}

A ACM é um método de redução de dados, que toma como entrada múltiplas variáveis categóricas e gera fatores. Este trabalho emprega STATA 10.0 para sua ACM. Já que o STATA permite apenas ponderações de frequência, converti para este artigo as ponderações de probabilidade, usadas para descrever características da classe média, em pesos de frequência. No fim, a ACM com ponderações de frequência produziu resultatos muitos parecidos da ACM sem ponderações. Este artigo adotou os resultados da ACM sem ponderações.

Existem três abordagens principais para a ACM, explicadas por Greenacre \& Blasius (2006: 27). A primeira é a matriz de Burt, que é uma matriz da tabulação cruzada bidirecional de todos os pares de variáveis; a segunda é a matriz de indicadores, em que os entrevistados são representados por categorias numa tabela com uma linha para cada entrevistado e uma coluna para cada categoria de resposta. A matriz de indicadores pode ser transformada numa matriz de Burt. A terceira, também recomendada por Greenacre (2006: 70-71), é a ACM ajustada, que unifica e corrige o problema do escalonamento, apresentando uma única solução independente da matriz considerada, com medição altamente melhorada da inércia. Já que a abordagem padrão do STATA para a ACM é a matriz de Burt, este artigo utilizou apenas esta.

O método de Burt é análogo à análise dos componentes principais, mas pode ser usado para variáveis categóricas. Ele executa uma análise de correspondência da matriz de Burt. Nesta, as variáveis ocorrem tanto como linhas quanto como colunas. Na página ao lado temos uma ilustração de uma matriz de Burt com duas variáveis.

Após obter o biplot para as 24 categorias, acrescentei variáveis suplementares ao espaço para examinar o modo como padrões de consumo estão correlacionados com indicadores socioeconômicos. Como Greenacre (2006: 31) explicou, variáveis suplementares não têm nenhuma influência sobre a orientação geométrica dos eixos; antes, apoiam e complementam a interpretação da configuração das categorias de variáveis ativas. Elas podem ser vistas como pontos adicionais nos espaços de perfil das linhas ou colunas; sua massa é igual a zero e não têm nenhuma importância para a análise além de interpretarem as suas posições (2006: 31). No caso da matriz de Burt, as coordenadas principais da coluna suplementar ${ }^{13}$ são derivadas como média ponderada das coordenadas de linha padrão, ponderadas pelo perfil suplementar. 


\begin{tabular}{|c|c|c|c|c|c|c|c|c|c|}
\hline & & \multicolumn{4}{|c|}{ Comer em um restaurante } & \multicolumn{4}{|c|}{$\begin{array}{l}\text { Fazer compras em lojas de } \\
\text { departamentos famosas }\end{array}$} \\
\hline & & 1 & 2 & 3 & 4 & 1 & 2 & 3 & 4 \\
\hline \multirow{4}{*}{$\begin{array}{l}\text { Comer em um } \\
\text { restaurante }\end{array}$} & 1 & 288 & 0 & 0 & 0 & 68 & 78 & 86 & 54 \\
\hline & 2 & 0 & 849 & 0 & 0 & 48 & 245 & 403 & 145 \\
\hline & 3 & 0 & 0 & 1.757 & 0 & 42 & 250 & 919 & 536 \\
\hline & 4 & 0 & 0 & 0 & 2.943 & 46 & 129 & 441 & 2.303 \\
\hline \multirow{4}{*}{$\begin{array}{l}\text { Fazer compras em lojas de } \\
\text { departamento famosas }\end{array}$} & 1 & 68 & 48 & 42 & 46 & 205 & 0 & 0 & 0 \\
\hline & 2 & 78 & 245 & 250 & 129 & 0 & 705 & 0 & 0 \\
\hline & 3 & 86 & 403 & 919 & 141 & 0 & 0 & 1.858 & 0 \\
\hline & 4 & 54 & 145 & 536 & 2.303 & 0 & 0 & 0 & 3.050 \\
\hline
\end{tabular}

1 Frequentemente | 2 Às vezes | 3 Ocasionalmente | 4 Nunca

Tabela 12: Ilustração da matriz de Burt com duas variáveis sobre a prática de consumo da CGSS 2003

Fonte: China General Social Survey 2003.

População: Todos os homens e mulheres entre 15 e 77 anos, que de fato residem na China urbana em 2003

Base: 5.894 .

Taxa de resposta: $77 \%$.

\section{O mapeamento dos padrões de consumo da população urbana em 2003}

Na execução da análise de correspondência múltipla, são produzidos quatro eixos sobre os 5.659 indivíduos. O eixo 1 explica 84,29\% da variação com uma inércia principal de 0,169, e o eixo 2 explica 9,67\% da variação com uma inércia principal de 0,019. Do eixo 3 obtemos pouca explicação de variação adicional (2,34\% para o eixo 3 e $0,02 \%$ para o eixo 4$)$, o que implica que os eixos 1 e 2 são os dois eixos mais importantes que precisam ser interpretados.

A proximidade do envolvimento em práticas de consumo da população urbana é revelada no Gráfico 1 [ver p. 225]. Pessoas que "frequentemente" comem num restaurante também fazem compras "frequentemente" em lojas de departamentos famosas, "frequentemente" adquirem produtos duráveis de marca para o lar, "frequentemente" usam itens artísticos para a decoração da casa e "frequentemente" vão à academia. Além disso, as frequências de praticar esses tipos de consumo "ocasionalmente", "às vezes" e "nunca" também se concentram em pontos respectivos. A categoria de "frequentemente comprar bens desnecessários", porém, é uma exceção, possivelmente devido à noção de "bens desnecessários" ser uma expressão ambígua e tenha confundido os entrevistados. Também apresenta uma conotação negativa e é, provavelmente, uma pergunta mal elaborada por este motivo. No entanto, executei uma ACM excluindo a variável "comprar bens desnecessários", e as posições relativas dos 
itens não sofreram basicamente nenhum efeito, tendo a inércia principal sido apenas levemente alterada. Por isso, decidi manter a variável para a análise. Mostra-se que os espaços sociais foram segregados pelos padrões de consumo. Os indicadores socioeconômicos são apresentados nos gráficos 2 e 3 .

É evidente que os grupos de idade e as classes sociais se posicionam firmemente ao longo do primeiro eixo [ver Gráfico 2, p. 226]. Da esquerda para a direita, as duas variáveis seguem o seguinte padrão: de empregos executivos para trabalhos manuais, de jovens para idades mais avançadas. A linha divisória entre os padrões de consumo pode ser traçada aproximadamente entre trabalhos não manuais (dirigentes, profissionais, empregados de escritório e comércio) e trabalhos manuais (pequenos empregadores, empregados florestais e agricultores, operadores e desempregados), e entre pessoas com menos de 36 e com mais de 36 anos de idade, referente às categorias alocadas à esquerda e à direita do eixo 1. A idade em particular é o fator mais importante que condiciona os atributos do padrão de consumo representado pelo eixo 1, pois a idade se encontra bem próxima ao eixo 1 e apresenta pouca distribuição vertical ao longo do eixo 2. Além disso, como ilustra a Gráfico 3 [ver p.227], os padrões de consumo das populações metropolitanas, incluindo tanto os migrantes quanto os nativos, estão mais próximos aos padrões de consumo dos trabalhos não manuais e das pessoas mais jovens (com menos de 36 anos), enquanto os padrões de consumo das "outras populações urbanas" estão mais próximos dos padrões dos trabalhos manuais e das pessoas mais velhas (com mais de 36 anos). As diferenças entre os migrantes metropolitanos e os nativos metropolitanos são menos significativas quanto à participação em práticas de consumo, e o impacto do fato de se viver em cidades metropolitanas é enfatizado. Daí, como descrito pelo eixo 1, a população mais jovem, com status social mais elevado e que vive em cidades metropolitanas participam com frequência maior em práticas de consumo.

Quanto ao eixo 2, a renda é o fator mais significativo que diferencia os padrões de consumo definidos por este eixo [ver Gráfico 3, p.227]. Ao longo do eixo 2, encontramos no topo a renda anual pessoal de pelo menos 60 mil yuan, e abaixo dela temos a renda entre 30 mil e 60 mil yuan por ano; os outros grupos de renda se concentram na parte inferior do eixo 2, mesmo que os grupos de renda baixa, de entre 5 mil-10 mil yuan por ano e abaixo de 5 mil yuan por ano, também estejam posicionados ao longo do eixo 1 . O grupo de renda de mais de 60 mil yuan por ano se encontra particularmente próximo às práticas de comer frequentemente num restaurante, de frequentemente fazer compras em lojas de departamentos famosas, de frequentemente comprar produtos de marca, de frequentemente decorar sua casa com itens artísticos e de frequentemente ir à academia. Correspondentemente, o grupo de renda "entre $30 \mathrm{mil}$ e 60 mil yuan" está próximo de praticar essas atividades "às vezes", e os outros grupos de renda estão próximos a "ocasionalmente" e "nunca". A posição das 
categorias de "ocasionalmente" é notavelmente interessante, pois se encontra próxima a trabalhos não manuais, a idade abaixo de 36 anos, a viver em cidades metropolitanas e a renda anual entre 30 mil e 10 mil yuan. Esse espaço indica que a tensão entre aspirações materiais e o poder de compra é mais significativo entre membros da classe média mais jovem nas cidades metropolitanas. Resumindo, podemos inferir do Gráfico 3 [ver p. 227] que o eixo 2 representa padrões de consumo intimamente correlacionados à renda - pessoas ricas optam mais frequentemente por bens materiais e serviços caros e de alta qualidade.

A análise da contribuição de cada modalidade às variações em cada eixo revelam mais aspectos das práticas de consumo da população urbana. De acordo com a Tabela 13 [ver p. 229], o eixo primário é mais frequentemente interpretado por "ocasionalmente" (35\%) e "nunca" (36,5\%), fato que indica que a população urbana como um todo permanece frugal e moderada em termos de consumo, apesar da emergência de uma nova orientação em direção a prazer e conforto pessoal. A maioria da contribuição do segundo eixo, porém, provém da prática "frequente" de atividades que visam a prazer e conforto, que respondem por 53,1\% da contribuição total. Já que o segundo eixo está intimamente associado à renda, este resultado reflete uma orientação mais significativa em direção a prazer e conforto pessoal entre membros da população rica. Portanto, a Tabela 13 [ver p. 229] confirma que a população urbana assume, em geral, uma atitude moderada e prática em relação ao consumo; as pessoas que dispõem de recursos econômicos abundantes usam seu dinheiro com maior frequência para a aquisição de bens materiais e serviços caros, mas essa dimensão apresenta uma influência menor.

\section{Discussão e implicações}

A orientação para prazer e conforto pessoal entre a população urbana na China está sugerida pelos resultados da pesquisa. A extensão da adoção dessa nova orientação do consumidor, porém, se apresenta de forma diferenciada entre os grupos socioeconômicos. Em particular, vários modos de participação "frequente" no consumo se apresentam de forma concentrada no mapa, mas se encontram distantes das categorias que "nunca" participam de práticas de consumo, e isso, em essência, é um reflexo da desigualdade social. Idade, classe social, renda e vida em cidades metropolitanas são, todos eles, fatores importantes para distinguir a orientação dos consumidores.

Disto, resultam várias implicações: (1) um efeito geracional é significativo nos padrões de consumo e reflete as mudanças sociais dramáticas que ocorrem na sociedade contemporânea. (2) A diferença na participação em práticas de consumo é mais significativa entre ocupações não manuais e manuais do que entre as próprias ocupações não manuais. A classe média, ou seja, "dirigentes do partido, organizações e instituições governamentais" e "profissionais e téc- 
nicos, funcionários comuns em posição intermediária do governo" participam com mais frequência do que a classe baixa em práticas de consumo em busca de prazer e conforto. A diferença entre classes sociais se reflete na literatura chinesa existente que fala do envolvimento da classe média com frequência e abrangência maiores com práticas de consumo na área de lazer (Wang, 2007; Horizon, 2006: 468). (3) O impacto da vida em cidades metropolitanas sobre as práticas de consumo é significativo, em alguma medida os gostos e estilos de vida dos migrantes são influenciados pelas cidades metropolitanas. (4) A renda exerce um papel menos importante na diferenciação da participação em práticas de consumo do que idade e classe social, já que o eixo 2, definido pela renda, apresenta uma variação muito menor do que o eixo 1 , definido pela idade e classe social; este resultado indica que o consumo não é apenas uma prática econômica, mas que é moldado por convenções e contextos sociais.

Além das consequências para a orientação em direção ao prazer e conforto pessoal, a análise também ressalta os aspectos distintivos da moderação e da frugalidade entre os membros da população urbana. Isto é um reflexo do status econômico menos elevado do país. E o que é ainda mais importante, isto também implica a troca intencional entre aspiração material e poder de compra entre a população que é associada à cultura tradicional. 




(\%L'6) Z Ooيحsuәш!p 


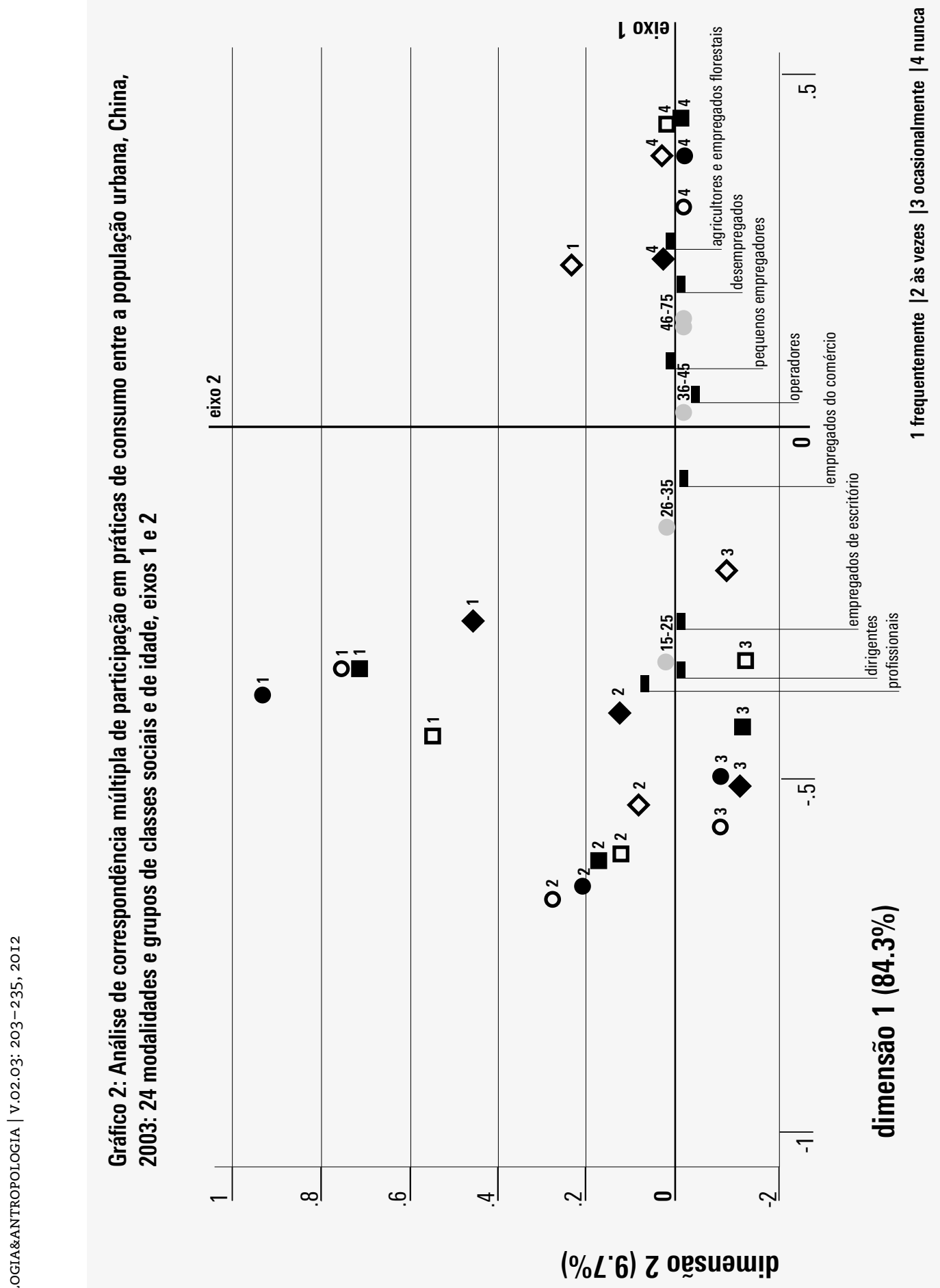




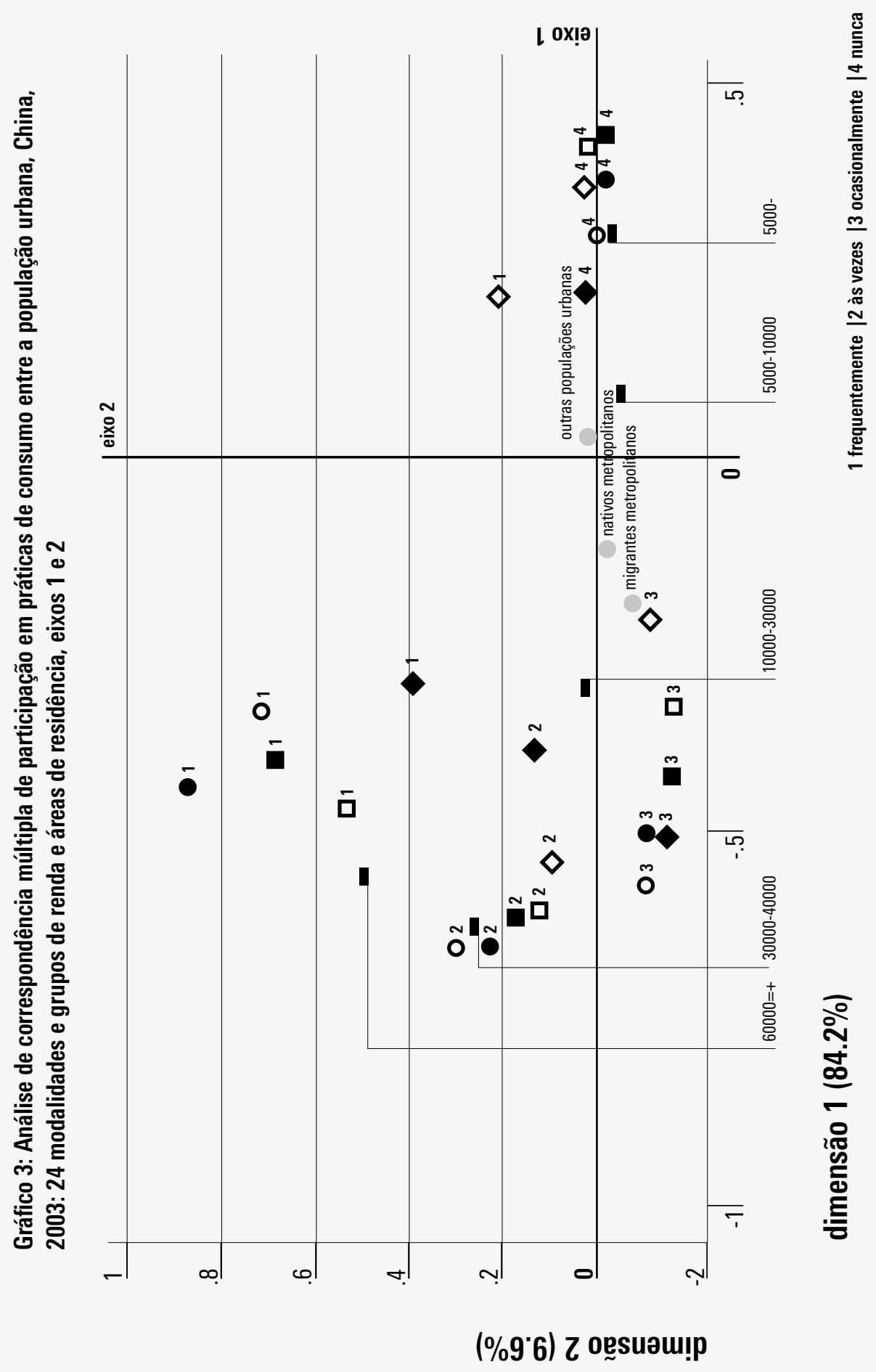




\section{CONCLUSÃO}

Este artigo discutiu as características demográficas da classe média em cidades metropolitanas e sua participação em práticas de consumo, baseando-se em dados de pesquisa. Mostrou-se que as diferenças entre migrantes metropolitanos e nativos metropolitanos são insignificantes quanto à conquista de status social e à participação em práticas de consumo. Pode-se então dizer que, apesar das diferenças econômicas serem grandes na China, o lugar de origem de uma pessoa dificilmente afeta as oportunidades ou estilos de vida da classe média em geral. Os resultados da pesquisa geraram implicações úteis referentes à orientação dos consumidores e suas diferenciações dentro da população. Uma orientação para prazer e conforto pessoal, moderada pela frugalidade, está emergindo na população urbana. A classe média, os jovens, a população metropolitana e os grupos de renda alta apresentam uma orientação mais significativa para prazer e conforto pessoais. Devido às limitações impostas pela fonte de dados, este artigo não pôde oferecer uma análise compreensiva da natureza e da extensão da orientação do consumidor. Pesquisas futuras poderão obter mais dados qualitativos a fim de examinar os motivos subjacentes à busca por prazer e conforto e para explicar como a classe média justifica seu consumo.

Artigo recebido para publicação em dezembro de 2011.

Zhu Di é PhD em Sociologia pela Universidade de Manchester. Trabalha no Instituto de Sociologia da Academia Chinesa de Ciências

Sociais. Suas áreas de pesquisa incluem sociologia do consumo, estratificação social, estudos de gênero e multimetodologia. É autora de, entre outros artigos, "The methodology and research strategies of mixed methods design and its application: in a case of study of consumption patterns" (2012); "A theoretical framework of sociology of consumption" (2012); e "Consumption patterns of the middle class 


\begin{tabular}{|c|c|c|c|c|c|c|c|c|c|c|}
\hline \multirow[t]{2}{*}{ Práticas de consumo } & \multicolumn{5}{|c|}{ Eixo 1} & \multicolumn{5}{|c|}{ Eixo 2} \\
\hline & 1 & 2 & 3 & 4 & Total & 1 & 2 & 3 & 4 & Total \\
\hline Comprar bens desnecessários & 5,6 & 1,5 & 5,1 & 0,3 & 12,5 & 0,3 & 4 & 1,1 & 2,8 & 8,2 \\
\hline $\begin{array}{l}\text { Ir a um restaurante em aniversários } \\
\text { ou durante festivais }\end{array}$ & 1,1 & 5,3 & 3,3 & 8,7 & 18,4 & 12,8 & 1,8 & 7 & 0 & 21,6 \\
\hline $\begin{array}{l}\text { Fazer compras em lojas de } \\
\text { departamentos famosas }\end{array}$ & 0,5 & 4,8 & 5,7 & 9,6 & 20,6 & 15,5 & 4 & 6,6 & 0 & 26,1 \\
\hline $\begin{array}{l}\text { Comprar produtos duráveis de } \\
\text { marca para o lar }\end{array}$ & 0,3 & 4,1 & 7,5 & 8,3 & 20,2 & 12,9 & 4,2 & 3,1 & 0 & 20,2 \\
\hline $\begin{array}{l}\text { Usar itens artísticos e pinturas } \\
\text { para a decoração do lar }\end{array}$ & 0,2 & 2,9 & 8,5 & 6 & 17,6 & 6,5 & 4,6 & 2,5 & 0 & 13,6 \\
\hline Ir à academia & 0,3 & 1,5 & 5,4 & 3,6 & 10,8 & 5,1 & 1,4 & 3,9 & 0 & 10,4 \\
\hline Total & 8,0 & 20,1 & 35,5 & 36,5 & 100,0 & 53,1 & 20,0 & 24,2 & 2,8 & 100,0 \\
\hline
\end{tabular}

1 Frequentemente | 2 Às vezes | 3 Ocasionalmente | 4 Nunca

Tabela 13: Contribuição das 24 modalidades às variações em cada eixo, CGSS 2003, análise de correspondência múltipla 


\section{NOTAS}

1 Estes são "bens de luxo" relativos ao fim da década de 1990 e de jovens. Os ítens listados pela pesquisa incluem gravadores de fita $\mathrm{K} 7$, bicicletas de esporte, motocicletas, pagers, joias de ouro puro, relógios de luxo, câmeras fotográficas e cartões de crédito.

2 O Tibete, uma unidade em nível de província, foi excluído do quadro de amostragem por motivos de praticabilidade para a realização da pesquisa (CGSS, 2003: 1).

3 Empregados em posições intermediárias e funcionários comuns do governo foram incluídos pela primeira vez nesta pesquisa (CGSS, 2003f). Por causa do status social de funcionários governamentais na China, eles também foram incluídos na categoria de "profissionais e técnicos".

4 Estes também foram incluídos pela primeira vez na pesquisa (CGSS, 2003f).

5 Essa estimativa é baseada em ocupações, incluindo funcionários do governo e partido, executivos, donos de empresas, técnicos especializados e empregados de escritórios.

6 Isto se refere àqueles que permaneceram ou permaneceriam durante muito tempo em cidades metropolitanas, e não apenas durante uma curta visita de alguns meses. Essa definição da população metropolitana não leva em consideração os registros oficiais de residência.

7 Devido ao status econômico menos desenvolvido em comparação com as outras três municipalidades, Chongqing foi excluída das cidades metropolitanas nesta análise.

8 Devido à migração crescente, $7,18 \%$ dos residentes apresentam um registro de residência rural nesta pesquisa urbana. Essa população consiste de pessoas que vivem há muito tempo nas cidades e de "visitantes temporários". Mas já que a amostragem é pequena, esta pesquisa integra estes entrevistados no grupo "outros residentes urbanos".

9 Já que não foi registrado nenhum caso de "dirigente" entre os migrantes, o teste $\mathrm{F}$ sobre a diferença entre os sexos não pode ser realizado para o grupo da classe média de migrantes. 
10 A renda anual corresponde à renda do ano anterior ao ano 2003 em que a pesquisa foi realizada.

11 No sistema da economia planificada, os filhos podiam ingressar na mesma unidade de trabalho após a aposentadoria dos seus pais. As unidades de trabalho que permitiam a herança de empregos eram normalmente empreendimentos estatais e consistiam principalmente de indústrias tradicionais.

12 As seis variáveis originais são seis afirmações sobre práticas de consumo: (1) Minha família e eu nunca compramos bens desnecessários. (2) Minha família e eu sempre vamos ao restaurante para celebrar aniversários ou alguma outra data importante. (3) Eu sempre faço compras em lojas de departamentos famosas. (4) A maioria dos bens duráveis em minha casa são de alta qualidade ou de marcas famosas. (5) Minha famíla usa muitos itens e pinturas artísticos para decorar nossa casa. (6) Eu vou muito à academia para me exercitar.

13 As coordenadas de linhas e colunas podem ser obtidas por meio de coordenadas padrão e coordenadas de princípio na ACM. A diferença entre os dois tipos de coordenadas está no valor de eixo calculado pela soma ponderada dos quadrados do conjunto de coordenadas. Ambos, porém, identificam pontos nas mesmas posições relativas. As coordenadas de princípio são escolhidas principalmente porque sua escala corresponde melhor aos dados.

\section{REFERÊNCIAS BIBLIOGRÁFICAS}

Bennett, Tonny; Savage, Mike; Silva, Elizabeth B. \& Warde, Alan. In: Gayo-Cal, Modesto \& Wright, David (orgs.). Culture, class, distinction. Londres: Routledge/ Taylor \& Francis Group, 2009.

Bourdieu, Pierre. Distinction: a social critique of the judgement of taste. Londres: Routledge \& Kegan Paul, 1984.

The forms of capital. In: Richardson, John G. (org.). Handbook of theory and research for the sociology of education. Nova York: Greenwood Press, 1986, p. 241-258.

The logic of practice. Cambridge: Polity Press, 1990. 
Chan, Tak Wing \& Goldthorpe, Jerry H. The social stratification of cultural consumption: some policy implications of a research project. Cultural Trends, 2007a, 16/4, p. 373-384.

Social stratification and cultural consumption: music in England. European Sociological Review, 2007b, 23/1, p. 1-19. Fan, Cindy C. Migration and labor-market returns in urban China: results from a recent survey in Guangzhou. Environment and Planning A, 2001, 33/3, p. 479-508.

The elite, the natives, and the outsiders: migration and labor market segmentation in urban China. Annals of the Association of American Geographers, 2002, 92/1, p. 103-124.

Rural-urban migration and gender division of labor in transitional China. International Journal of Urban and Regional Research, 2003, 27/1, p. 24-47.

Fan, Chengze Simon. Economic development and the changing patterns of consumption in urban China. In: Chua, BengHuat (org.). Consumption in Asia: lifestyles and identities. Londres/Nova York: Routledge, 2000, p. 82-97.

Fang, Ruifeng; Miller, Erica; Trieu, Huong \& Yang, Xiaoying. Migrant labor and social welfare policy, 2006. Disponível em < http://ebookbrowse.com/11-migrant-labor-and-social-welfare-policy-pdf-d130989945>. Acesso 23 abr. 2012.

Gayo-Cal, Modesto; Savage, Mike \& Warde, Alan. A cultural map of the United Kingdom, 2003. Cultural Trends, 2006, 15/2-3, p. 213-237.

Greenacre, Michael. From simple to multiple correspondence analysis. In: Greenacre, Michael \& Blasius, Jörg (orgs.). Multiple correspondence analysis and related methods. Londres: Chapman \& Hall/CRC, 2006, p. 41-76.

Greenacre, Michael \& Blasius, Jörg (orgs.). Multiple correspondence analysis and related methods. Londres: Chapman \& Hall/ CRC, 2006.

Guo, Fei \& Iredale, Robyn R. The impact of Hukou status on migrants' employment. Findings from the 1997 Be Migrant Census. International Migration Review, 2004, 38/2, p. 709-731.

Hoffman, Donna L. \& Leeuw, Jan de. Interpreting multiple correspondence analysis as a multidimensional scaling method. Marketing Letters, 1992, 3/3, p. 259-272. 
Horizon, Research. 中国消费文化调查报告 [Relato sobre a cultura de consumo na China]. 北京, 光明日报出版社, 2006.

Huang, Jing Hua; Yang, XueRui \& Lü, Ming Jie. 多种形态的 中国城市消费者 [Os heterogêneos consumidores urbanos chineses]. 北京, 中国轻工业出版社, 2003.

Li, Chun Ling. 中国当代中产阶层的构成及比例 [Estrutura e escala da classe média contemporânea na China]. 中国 人口科学, 2003, 6, p. 25-32.

Li, Qiang. 关于中产阶级和中产阶层 [Sobre a classe média e o estrato médio]. 中国人民大学学报, 2001, 2, p. 17-20.

Liu, Shi-Xiong. 中国消费区域差异特征分析：基于中国当代 文化价值的实证研究_[Análise dos padrões de consumo na China em relação às diferenças regionais: Pesquisa empírica sobre os valores culturais na China contemporânea]. 上海 [Xangai]: 三联书店 [Sdxjoint Publishing Company], 2007.

Marx, Karl. Classes in capitalism and pre-capitalism. In: Grusky, David B. (org.). Social stratification: class, race, and gender in sociological perspective. São Francisco/Oxford: Westview Press/Boulder, [1848] 2000.

Sassatelli, Roberta. Consumer culture: history, theory, politics. Londres: Sage Publications, 2007.

Saunders, Peter. Social class and stratification. Londres: Routledge, 1990.

Sorensen, Aage B. The basic concepts of stratification research: class, status, and power. In: Grusky, David B. (org.). Social stratification: class, race, and gender in sociological perspective. São Francisco/Oxford: Westview Press/ Boulder, 1994.

Stewart, Alexander; Prandy, Kenneth \& Blackburn, Robert Martin. Social stratification and occupations. Londres: Macmillan, 1980.

Wang, Jian Ping. 中国城市中间阶层消费行为 [Comportamento de consumo da classe média na China urbana]. 北京, 中国大百科全书出版社. 2007

Wei, Hou Kai. 改革开放30年中国区域经济的变迁一一从不 平衡发展到相对均衡发展 (上) [Transições na economia 
regional da China nos trinta anos desde as reformas - do desenvolvimento desequilibrado ao desenvolvimento relativamente equilibrado (1)]. 经济学动态, 2008. Disponível em <http://www.cre.org.cn/cre2007/Article/ShowArticle. asp? ArticleID=3820> . Acesso em 1 jul. 2010.

Zhang, Yu Fa. 20 世纪前半期的中国社会变迁(1900 1949) [Transições sociais da China na primeira metade do século XX (1900-1949)].”史学月刊, 2006, 3, p. 82-90.

\section{Referências para os dados de pesquisa}

CGSS. Chinese general social survey 2003: sampling design, 2003a. Disponível em <http://www.ust.hk/ websosc/survey/ GSS2003e3.html>. Acesso em 5 abr. 2012.

CGSS. China general social survey 2003: project description, 2003b Disponível em <http://www.ust.hk/ websosc/survey/ GSS2003e1.html>. Acesso em 5 abr. 2012.

CGSS. China general social survey 2003: survey implementation, 2003c. Disponível em <http://www.ust.hk/ websosc/survey/ GSS2003e4.html>. Acesso em 5 abr. 2012.

CGSS. China general social survey 2003: questionnaires and interviewer manual, 2003d. Disponível em <http://www.ust. hk/ websosc/survey/GSS2003e2.html>. Acesso em 5 abr. 2012.

CGSS. China general social survey 2003: codebook. Renmin University, 2003e.

CGSS. Occupation classification and codes 2000, 2003f. Disponível em <http://www.ust.hk/ websosc/survey/GSS2003e5. html>. Acesso em 5 abr. 2012.

CGSS. Industry classification and codes, 2003g. Disponível em <http://www.ust.hk/ websosc/survey/GSS2003e5.html>. Acesso em 5 abr. 2012. 


\begin{abstract}
Palavras-chave: Resumo:
Classe média; China; Este artigo enfoca as oportunidades de vida e a orientação Migrantes; Consumo; dos consumidores da classe média na China, além de exaAnálise de correspondência minar suas características e sua participação nas práticas múltipla. de consumo. Os dados foram fornecidos pelo China General Social Survey 2003. Devido a disparidades econômicas significativas entre as regiões, este artigo volta sua atenção para a divisão entre migrantes e habitantes nativos em cidades metropolitanas, que apresentam mais posições de classe média e onde a cultura de consumo prospera mais. A minha pesquisa mostrou que as diferenças entre os migrantes metropolitanos e os nativos metropolitanos são irrelevantes quanto à conquista de status social e participação nas práticas de consumo. Pode-se inferir que os migrantes metropolitanos são motivados a alcançar uma classe social ou uma renda mais alta e que seus gostos e estilos de vida são influenciados pelas cidades metropolitanas após sua migração. Mesmo que a frugalidade continue sendo um aspecto característico da população urbana chinesa, a classe média, os jovens e os grupos de renda alta apresentam uma forte orientação para o prazer e conforto pessoal.
\end{abstract}

Keywords:

Middle class; China; Migrants; Consumption; Multiple correspondence analysis.

\section{Abstract:}

This paper focuses on the life chances and consumer orientation of the chinese middle class by examining their characteristics and participation in consumption practices. Data comes from the China General Social Survey 2003. Due to significant economic disparities among regions, this paper draws attention to the division between the migrants and the natives in metropolitan cities, where there are more middle class positions and consumer culture more flourishes. The finding is that the differences between the metropolitan migrants and the metropolitan natives are insignificant in social status attainment and participation in consumption practices. It might be implied that the metropolitan migrants are motivated to achieve higher social class or income and their tastes and lifestyles are influenced by metropolitan cities after migration. Although frugality remains a distinguishing feature of the urban Chinese population, the middle class, the young people and the high-income groups display a more significant orientation to personal pleasure and comfort. 